\title{
Predictive model for early complications of acute myocardial infarction in patients with type 2 diabetes mellitus
}

\author{
Mariia Yuriivna Koteliukh ${ }^{1, *(1)}$, Olena Hryhorivna Dorosh ${ }^{2}$
}

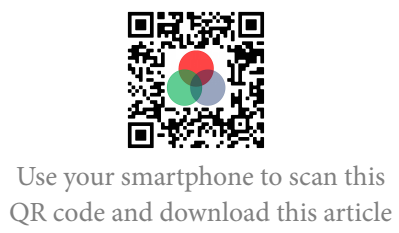

${ }^{1}$ Academician L.T. Malaya Department of Internal Medicine No. 2, Clinical Immunology and Allergology, Kharkiv National Medical University, 4, Nauky Avenue, Kharkiv, Ukraine

${ }^{2}$ Endocrinology Clinic of State Institution "V. Danilevsky Institute for Endocrine Pathology Problems of the National Academy of Medical Sciences of Ukraine", Alchevskyh st., 10, Kharkiv, Ukraine

\section{Correspondence}

Mariia Yuriivna Koteliukh, Academician L.T. Malaya Department of Internal Medicine No. 2, Clinical Immunology and Allergology, Kharkiv National Medical University, 4, Nauky Avenue, Kharkiv, Ukraine

Email: koteliukh@gmail.com

\section{History}

- Received: Nov 13, 2021

- Accepted: Jan 30, 2022

- Published: Feb 28, 2022

DOI : 10.15419/bmrat.v9i2.729

\section{Check for updates}

\section{Copyright}

(c) Biomedpress. This is an openaccess article distributed under the terms of the Creative Commons Attribution 4.0 International license.

\begin{abstract}
Introduction: Early complications of acute myocardial infarction (AMI) are one of the leading causes of death among patients with type 2 diabetes mellitus (DM). Clinical and laboratory characteristics and noninvasive methods need to be integrated to better identify early complications of AMI and further develop a treatment strategy. The aim of the study was to predict the development of early complications after AMI in type 2 DM patients, which could improve the quality of preventive and curative measures for this group of patients. Methods: In total, 109 patients with ST-elevation myocardial infarction (STEMI) and type 2 DM were included in the study: 75 men and 34 women. The training set $(n=74)$ was selected to study variables associated with the probability of early complications after AMI in type 2 DM patients. The model reproducibility was then checked on the validation set $(n=35)$. All patients underwent percutaneous coronary intervention $(\mathrm{PCI})$. The training set identified 26 patients with early complications and 48 patients without early complications of AMI. The validation set identified 18 patients with early complications and 17 patients without early complications of AMI. The model for predicting early AMI complications was calculated using binary logistic regression. Results: The developed mathematical model for predicting early complications of AMI was as follows: $P=[1+\exp (-(0.030 \times C 1$ q tumor necrosis factor-related protein $3(\mathrm{CTRP} 3)(\mathrm{ng} / \mathrm{ml})+1.414 \times$ respiratory rate $(\mathrm{RR})$ (breaths per minute) $+0.322 \times$ body mass index $(\mathrm{BMI})(\mathrm{kg} / \mathrm{m} 2)+0.091 \times$ heart rate $(\mathrm{HR})$ (beats per minute) -50.800$))]^{-1}$. The model yielded the highest results under the receiver operating characteristic curve for predicting early complications of AMI among the diabetic patients in both the training and validation groups (0.962 and 0.928 , respectively). Conclusions: This study has shown that integral measurements of circulating CTRP 3 content, RR, BMI, and HR upon admission of STEMI patients with type $2 \mathrm{DM}$ after PCI could predict early complications of AMI. These findings suggest a new approach to stratify the risk of early AMI complications in type 2 DM patients after successful coronary revascularization.

Key words: Complications, diabetes mellitus, myocardial infarction, predictive model
\end{abstract}

\section{INTRODUCTION}

Cardiovascular diseases (CVDs) are one of the leading causes of death in today's world. According to the World Health Organization, CVDs remain at the top of ten leading causes of death, and diabetes mellitus (DM) was first inscribed in this list in 2020. CVD mortality rates increased by more than 2 million cases in 2019 compared to 2000 and reached 8.9 million cases worldwide. Acute myocardial infarction (AMI) is one of the most dangerous CVDs and can be fatal. During the period from 2000 to 2019, DM-associated mortality increased by $70 \%$ worldwide, with $80 \%$ in males ${ }^{1}$. The risk of developing early complications of AMI is significantly increased in type $2 \mathrm{DM}$ comorbidity, which worsens the course and prognosis of AMI. Patients with AMI and type 2 DM are more likely to develop early complications, such as acute heart failure (AHF), arrhythmic complications and, as a result, death during hospitalization. A significantly higher mortality rate has been demonstrated in type 2 DM patients with AMI complicated by cardiogenic shock compared to those without type $2 \mathrm{DM}^{2,3}$. As concluded by Khalid SH. et al. ${ }^{4}$, AMI patients with type $2 \mathrm{DM}$ experienced a higher prevalence of adverse cardiovascular events, pointing out the necessity of an individual management strategy for such patients on the first day of hospital stay. Early reperfusion and medication effectively reduced the development of acute complications of AMI. However, despite remarkable treatment success, early complications of AMI continue to occur in patients with AMI and type $2 \mathrm{DM}$. The only possibility to prevent longterm adverse outcomes are early predictions of these complications and timely treatment for high-risk patients. Even today, despite the current conditions of treatment with a wide range of methods used with proven effectiveness, the clinical and laboratory parameters predicting early complications of AMI in pa- 
tients with type 2 DM remain uncertain. Early identification of patients at high risk for early complications of AMI is extremely important because targeted treatment strategies in the early stages of AMI can prevent the development of these complications. The prediction of early complications after AMI is aimed at facilitating the restoration of functional myocardium and systemic hemodynamics and requires careful study. Patients with AMI and type 2 DM should be specifically managed, as they are more commonly found to have adverse cardiovascular events.

Accumulated data suggest that adipose tissue is not just a tissue for energy storage but also a secretory tissue that produces adipokines. The balance between proinflammatory and protective adipokines is impaired in type $2 \mathrm{DM}$, and adipose tissue dysfunction can be considered ${ }^{5}$. Clq tumor necrosis factor-related protein-3 (CTRP3 or cartonectin) is an anti-inflammatory adipokine that affects carbohydrate and lipid metabolism, regulates the secretion of other adipokines and exhibits cardioprotective properties ${ }^{6}$. CTRP3 is associated with cardiovascular disease and type $2 \mathrm{DM}^{7}$. The CTRP3 mechanism of action on cardiomyocytes is mediated by a number of signaling pathways. CTRP3 has been shown to increase the expression of nuclear receptor peroxisome proliferator activated receptor (PPAR)-alpha and PPAR-gamma coactivator-1alpha, phosphorylation of 5'adenosine monophosphate-activated protein kinase, Akt in the heart, and attenuate cardiac fibrosis by inhibiting myofibroblast differentiation and subsequent extracellular matrix production ${ }^{8-11}$. In contrast, in another study, CTRP3 promoted the activation of signaling pathways, namely, PI3K, Akt and endothelial nitric oxide synthase ${ }^{12}$. The effect of CTRP3 on cardiac fibrosis was examined, and significantly decreased CTRP3 expression after AMI was determined. Moradi Nariman et al. found a reduced concentration of CTRP3 in type 2 DM patients ${ }^{13}$. Ahmed SF. et al. and Kratochvilova H. et al. noted that CTRP3 could be both a diagnostic marker and a prognostic marker in the development of coronary heart disease in type $2 \mathrm{DM}$ patients ${ }^{14,15}$. However, the relationship between CTRP3 and the occurrence of early complications in type $2 \mathrm{DM}$ patients after AMI remains poorly understood.

Therefore, the aim of the present study was to predict the development of early complications after AMI in type 2 DM patients using binary logistic regression, which could improve the quality of diagnostic and therapeutic measures for this group of patients.

\section{METHODS}

\section{Study population}

A total of 109 patients with ST-elevation myocardial infarction (STEMI) and 2 types of DM were included in the study. All the patients received treatment at the State Institution "L.T. Malaya National Therapy Institute of the National Academy of Medical Sciences of Ukraine" and the Kharkiv Railway Clinical Hospital No. 1 of the branch "Center of Healthcare" of Public Joint Stock Company "Ukrainian Railway" from 01 September 2018 to 31 December 2020. The study entailed clinical assessment of the patient's condition, CTRP3 quantification and prediction of the incidence of early AMI complications in type 2 DM patients. All patients were diagnosed with AMI, underwent diagnostic measures for the detection of early AMI complications and were prescribed treatment according to the European recommendations of cardiologists ${ }^{16}$. The concept of early complications of AMI included the presence of atrioventricular (AV) blockade, atrial fibrillation (AF), ventricular fibrillation (VF), AHF Killip classes II, III, IV, acute left ventricular aneurysm (LVA) of the apex and interventricular septum, and reduced ejection fraction (EF) of the left ventricle $(\mathrm{LV})<40 \%$. All patients underwent percutaneous coronary intervention (PCI). Diagnosis and treatment of type $2 \mathrm{DM}$ was performed according to joint recommendations of the American Diabetes Association, the European Association for the Study of DM $(2018,2019)$ and the criteria of the International Diabetes Federation (2019) ${ }^{17-21}$.

Inclusion criteria were specified for acute STEMI and type 2 DM: age $\geq 45$ years and the absence of contraindications to PCI. All 109 patients met these criteria.

Cases of diagnosed severe comorbidities (type 1 DM, autoimmune diseases, myocardial infarction secondary to functional class IV chronic heart failure, chronic obstructive pulmonary disease, bronchial asthma, heart valve disease, symptomatic hypertension, severe liver and kidney dysfunction, severe anemia, bleeding), severe acute respiratory syndromerelated coronavirus 2 , malignancy, and inability to give written informed consent were excluded from the present study.

\section{Clinical characteristics}

In total, 109 participants were included in the study: 75 men $(68.8 \pm 4.4)$ and 34 women $(31.2 \pm 4.4)$. Overall, the vast majority of patients were overweight, and all patients had hypertension. 
A training set $(\mathrm{n}=74)$ was selected to study variables associated with the probability of early complications after AMI in type $2 \mathrm{DM}$ patients. The model reproducibility was checked on a validation set $(\mathrm{n}=$ 35). The training set identified 26 patients with early complications and 48 patients without early complications of AMI. The validation set identified 18 patients with early complications and 17 patients without early complications of AMI. All patients underwent PCI.

The purpose of each examination was explained in detail, and informed consent was obtained from all participants. The study protocol was approved by the Bioethical Committee of Kharkiv National Medical University (Protocol No. 2 dated 02 April 2018) and performed according to the 1975 Declaration of Helsinki (the 6th revision, 2008).

\section{Enzyme-linked immunosorbent assay}

All studies were performed in the Biochemical Department of the Central Research Laboratory of Kharkiv National Medical University. Serum samples from patients were collected on days $1-2$ and stored at $-80{ }^{\circ} \mathrm{C}$. Serum CTRP3 content was measured by enzyme-linked immunosorbent assay using an analyzer "Labline-90" (Austria) with a commercial test system "Human CTRP 3" manufactured by Aviscera Bioscience Inc., Santa Clara, USA, following the manufacturer's instructions. The CTRP3 content quantification is based on a sandwich assay principle, characterized by an antibody pair of the capture antibody (immobilized) and biotin-labeled detection antibody binding to captured analyte. To stabilize the CTRP3 polymer, serum samples were treated with 0.5 M Tris (2-carboxyethyl) phosphine hydrochloride solution in a special buffer before the assessment. After that, $100 \mu \mathrm{l}$ of calibration solutions, standards and test samples were added to the appropriate wells of a special plate supplied with the kit. The plate was incubated for 2 hours at room temperature on a shaker. Then, the cells were washed 3 times with washing buffer, and $100 \mu$ l of antibody reaction mixture was added to each well. The plate was again incubated for 2 hours at room temperature. The wells were washed again 3 times with washing buffer, and 100 $\mu l$ of streptavidin-horseradish peroxidase conjugate was added to each well. The plate was incubated for 60 minutes at room temperature, and all wells were washed again 3 times as before. Then, $100 \mu \mathrm{l}$ of substrate solution was added to each well and left for 18 minutes in the dark at room temperature. The reaction was stopped by adding $100 \mu \mathrm{l}$ of stop reagent to each well. The optical density of each sample was measured at a wavelength of $450 \mathrm{~nm}$ (reference filter $630 \mathrm{~nm}$ ) over 5 minutes. CTRP3 quantification was performed according to the calibration curve, which was constructed in parallel with the samples using kit calibrator buffer. The CTRP3 content was expressed in nanograms per milliliter of serum $(\mathrm{ng} / \mathrm{ml})$. We determined the mean and reference range for CTRP 3 to be 325.97 (274.59 - 399.96) ng/ml.

\section{Instrumental methods of examination}

Obesity was diagnosed according to body mass index (BMI) by the following formula: weight $(\mathrm{kg}) /$ height $\left(\mathrm{m}^{2}\right)$ and was detected if the BMI was equal to or exceeded $30 \mathrm{~kg} / \mathrm{m}^{2}$. The normal body weight ranged from 18.5 to $24.9 \mathrm{~kg} / \mathrm{m}^{2}$. To determine obesity and the type of adipose tissue distribution, the waist circumference (WC)-to-thigh circumference (TC) ratio (WC/TC) was calculated. Minimum WC was measured in the middle between the navel and rib cage; the measurement of TC was performed directly below the gluteal fold (the thickest part of the thigh). Normal values according to the classification were $\mathrm{WC}<$ $94 \mathrm{~cm}$ for men and $<80 \mathrm{~cm}$ for women. WC/TC index $\geq 0.90$ for men and $\geq 0.85$ for women was considered a sign of abdominal obesity ${ }^{22,23}$. Doppler echocardiography was performed according to the conventional method on an ultrasound scanner Radmir ULTIMA Pro30 (Ukraine). Standard 12-lead electrocardiography was performed using a three-channel electrocardiograph "Fukuda" FX-326U (Japan).

\section{Statistical data processing}

Statistical processing of the obtained data was performed using the computer software IBM SPPS version 27.0 (2020) (IBM Inc., USA, license No. LCZAA-BKKMKE). The studied parameters regarding the normality of the distribution were assessed according to the Kolmogorov-Smirnov criterion. Statistical analysis involved quantitative and qualitative variables. Qualitative data are presented as percentages; quantitative data are presented as medians and interquartile ranges $\left(25^{\text {th }}\right.$ and $75^{\text {th }}$ percentiles). The nonparametric Mann-Whitney rank test was used to compare quantitative indicators. The frequency of signs in the groups was compared using the Pearson $\chi 2$ test. The critical level of significance for testing statistical hypotheses in the study was 0.05 .

A prognostic model for detecting early complications of AMI in the presence of type 2 DM was developed based on the data obtained from the training set and then tested using the validation set data. The patients 
Table 1: Baseline characteristics of 109 patients with acute myocardial infarction and type 2 diabetes mellitus

\begin{tabular}{|c|c|c|c|c|}
\hline \multicolumn{2}{|l|}{ Variable } & $\begin{array}{l}\text { Training group } \\
\quad(\mathrm{n}=74)\end{array}$ & $\begin{array}{l}\text { Validation group } \\
\qquad(\mathrm{n}=35)\end{array}$ & $\begin{array}{l}\text { All patients } \\
\qquad(\mathrm{n}=109)\end{array}$ \\
\hline \multirow[t]{2}{*}{ Sex, n (\%) } & & $51(68.9 \pm 5.4)$ & $24(68.6 \pm 7.8)$ & $75(68.8 \pm 4.4)$ \\
\hline & ale & $23(31.1 \pm 5.4)$ & $11(31.4 \pm 7.8)$ & $34(31.2 \pm 4.4)$ \\
\hline \multicolumn{2}{|l|}{ Age, years } & $60.0(52.0-66.25)$ & $62.0(58.0-67.0)$ & $61.0(54.5-67.0)$ \\
\hline \multicolumn{2}{|l|}{ BMI, $\mathrm{kg} / \mathrm{m}^{2}$} & $28.1(26.0-31.1)$ & $28.4(26.0-32.0)$ & $28.2(26.0-32.0)$ \\
\hline \multicolumn{2}{|l|}{ Height, cm } & $\begin{array}{c}170.0(165.0- \\
178.0)\end{array}$ & $\begin{array}{c}168.0(163.0- \\
175.0)\end{array}$ & $170.0(165.0-176.0)$ \\
\hline \multicolumn{2}{|l|}{ Weight, kg } & $85.0(75.75-92.0)$ & $80.0(75.0-90.0)$ & $83.0(75.0-92.0)$ \\
\hline \multicolumn{2}{|l|}{$\mathrm{WC}, \mathrm{cm}$} & $\begin{array}{l}98.0(86.75- \\
115.75)\end{array}$ & $117.0(78.0-120.0)$ & $100(86.0-118.0)$ \\
\hline \multicolumn{2}{|l|}{$\mathrm{TC}, \mathrm{cm}$} & $\begin{array}{c}110.0(102.0- \\
112.0)\end{array}$ & $\begin{array}{c}113.0(100.0- \\
130.0)\end{array}$ & $110.0(102.0-115.0)$ \\
\hline \multicolumn{2}{|l|}{ WC/TC } & $0.89(0.84-0.99)$ & $0.94(0.83-1.05)$ & $0.90(0.84-0.99)$ \\
\hline \multicolumn{2}{|l|}{$\mathrm{RR}, \mathrm{bpm}$} & $17.5(17.0-18.0)$ & $19.0(17.0-20.0)$ & $18.0(17.0-20.0)$ \\
\hline \multicolumn{2}{|l|}{ HR, bpm } & $80.0(70.0-100.0)$ & $76.0(74.0-84.0)$ & $80.0(71.0-93.0)$ \\
\hline \multicolumn{2}{|l|}{ Overweight, n (\%) } & $31(41.9 \pm 5.7)$ & $19(54.3 \pm 8.4)$ & $50(45.9 \pm 4.8)$ \\
\hline \multicolumn{2}{|l|}{ Obesity, n (\%) } & $31(41.9 \pm 5.7)$ & $15(42.9 \pm 8.4)$ & $46(42.2 \pm 4.7)$ \\
\hline \multicolumn{2}{|l|}{ Hypertension, n (\%) } & $74(100)$ & $35(100)$ & $109(100)$ \\
\hline \multicolumn{2}{|l|}{ Active smoking, n (\%) } & $10(13.5 \pm 3.9)$ & $5(14.3 \pm 5.9)$ & $15(13.8 \pm 3.3)$ \\
\hline \multicolumn{2}{|l|}{ Prior MI, n (\%) } & $13(17.6 \pm 4.4)$ & $6(17.1 \pm 6.4)$ & $19(17.4 \pm 3.6)$ \\
\hline \multirow[t]{4}{*}{ AHF, Killip class, $\mathrm{n}$} & I & $60(81.1 \pm 4.6)$ & $28(80.0 \pm 6.7)$ & $88(80.7 \pm 3.8)$ \\
\hline & II & $6(8.1 \pm 3.2)$ & $3(8.6 \pm 4.7)$ & $9(8.3 \pm 2.6)$ \\
\hline & III & $6(8.1 \pm 3.2)$ & $3(8.6 \pm 4.7)$ & $9(8.3 \pm 2.6)$ \\
\hline & IV & $2(2.7 \pm 1.9)$ & $1(2.8 \pm 2.8)$ & $3(2.8 \pm 1.6)$ \\
\hline \multicolumn{2}{|l|}{ LVEF, \% } & $50.0(45.0-55.25)$ & $53.0(48.0-56.0)$ & $51.0(45.0-56.0)$ \\
\hline \multicolumn{2}{|l|}{$\mathrm{LVEF} \leq 40, \mathrm{n}(\%)$} & $9(12.2 \pm 3.8)$ & $4(11.4 \pm 5.4)$ & $13(12.0 \pm 3.1)$ \\
\hline \multicolumn{2}{|l|}{$\mathrm{AF}, \mathrm{n}(\%)$} & $6(8.1 \pm 3.2)$ & $3(8.6 \pm 4.7)$ & $9(8.3 \pm 2.6)$ \\
\hline \multicolumn{2}{|l|}{ VF, n (\%) } & $3(4.1 \pm 2.3)$ & $1(2.8 \pm 2.8)$ & $4(3.7 \pm 1.8)$ \\
\hline \multicolumn{2}{|l|}{ AV block, n (\%) } & $1(1.4 \pm 1.3)$ & $1(2.8 \pm 2.8)$ & $2(1.8 \pm 1.3)$ \\
\hline \multicolumn{2}{|l|}{ LVA, n (\%) } & $2(2.7 \pm 1.9)$ & $1(2.8 \pm 2.8)$ & $3(2.8 \pm 1.6)$ \\
\hline \multicolumn{2}{|c|}{$\begin{array}{l}\text { CTRP3 content on day } 1 \text {, } \\
\mathrm{ng} / \mathrm{ml}\end{array}$} & $\begin{array}{c}218.32(191.95- \\
268.68)\end{array}$ & $\begin{array}{c}233.8(226.7- \\
249.7)\end{array}$ & $230.8(193.7-259.6)$ \\
\hline
\end{tabular}

Data are presented as medians and interquartile ranges $\left(25^{\text {th }}\right.$ and $75^{\text {th }}$ percentiles $)$ and percentage error.

Abbreviations: AF: atrial fibrillation; AHF: acute heart failure; AV block: atrioventricular blockade; CTRP3: C1q tumor necrosis factor-related protein 3; LVA: left ventricular aneurysm; LVEF: left ventricular ejection fraction; MI: myocardial infarction; VF: ventricular fibrillation; WC: waist circumference; TC: thigh circumference; WC/TC: ratio of waist to thigh circumference; RR: respiratory rate, breaths per minute; HR: heart rate, beats per minute; BMI: body mass index

were randomized to the training and validation sets at a ratio of $68 \%$ to $32 \%$. Binary logistic regression was used to construct the model for predicting early complications in type $2 \mathrm{DM}$ patients with AMI. Regression coefficients were calculated for each factor. The significance of a difference between the coefficients and zero was checked using Wald's statistics. The model performance was assessed using Nagelkerke $\mathrm{R}^{2}$. The Hosmer-Lemeshow test was applied for calibration processing to test the goodness of fit for the hypothesis that the model and the obtained findings were in agreement. The synthesized mathematical model performance was evaluated with receiver operating characteristic (ROC) analysis. 


\section{RESULTS}

\section{Patient characteristics}

The model was constructed based on the data obtained from the training group and verified with the validation group. No difference in baseline characteristics was found between the two groups. The characteristics of the patients, including demographic, clinical and laboratory parameters, are shown in Table 1. In the study, the majority of patients were male $(68.8 \%$ \pm 4.4 ). Overweight and obese were $50 \% \pm 4.8$ and $46 \% \pm 4.7$, respectively. Hypertension was observed in all patients. Most patients $(96.3 \% \pm 1.8)$ had preserved LV systolic function. Low CTRP 3 levels on day 1 in type $2 \mathrm{DM}$ patients with AMI were determined according to CTRP 3 reference values.

\section{A novel model for the assessment of early complications in type 2 DM patients with AMI}

To develop a mathematical model, the study included 74 patients (training group) who were divided into subgroups: the $1^{\text {st }}$ subgroup consisted of 48 patients without early complications, and the $2^{\text {nd }}$ subgroup involved 26 patients with early complications. The most important indicators for constructing the model were CTRP3, respiratory rate (RR), BMI, and heart rate (HR). Binary logistic regression was used to obtain the mathematical model to determine the probability of developing early complications $(\mathrm{P})$ by type $2 \mathrm{DM}$ patients with AMI: $\mathrm{P}=[1+\exp (-(0.030 \times \mathrm{CTRP} 3)$ $(\mathrm{ng} / \mathrm{ml})+1.414 \times \mathrm{RR}$ (breaths per minute) +0.322 $\times$ BMI $(\mathrm{kg} / \mathrm{m} 2)+0.091 \times$ HR (beats per minute) $50.800))]^{-1}$.

The value of $\mathrm{P}$ ranged from 0 to 1 . The closer to 1 , the higher the probability of early complications. The coefficients of the selected mathematical model are given in Table 2. All variables, according to Wald's criterion, were significant $(\mathrm{p}<0.05)$ and selected correctly.

The model as a whole and its individual coefficients were statistically significant; the Nagelkerke R-square value was 0.803 , and the correctness of the model predictability was 80.3 . The achieved significance level of the Hosmer-Lemeshow goodness of fit test was $\mathrm{p}=$ 0.605 ( $p>0.05$ ), indicating a high degree of adequacy of the developed model to the data obtained.

Classification Table 3 provides a possibility to make a conclusion concerning the number of correct and incorrect predictions. The table shows that out of the total number of patients without early complications, equal to 48 , the test correctly identified 47 patients, and 1 person was incorrectly assigned to the group with early complications. Of the total number of patients with early complications, equal to 26,22 patients were correctly identified, and 4 were incorrectly assigned to the group of patients without complications. In total, 69 cases out of 74 were recognized correctly, comprising $93.2 \%$.

The area under the ROC curve (AUC) for model diagnostic value estimation was 0.962 [0.919; 1.000], which indicated a very good quality of the model (Figure 1A). The usefulness of the mathematical model was tested in practice for predicting the development of early complications in the validation group. We examined 35 patients who were divided into subgroups: the $1^{\text {st }}$ subgroup consisted of 17 patients without early complications, and the $2^{\text {nd }}$ subgroup comprised 18 patients with early complications. The results of the model evaluation are shown in Table 4.

According to the results obtained from 33 examined patients, the prediction was correct, so it was confirmed in $94.3 \%$ of cases. The AUC-ROC was 0.928 $[0.829 ; 1,000]$, reflecting a high accuracy of prediction (Figure 1B).

\section{DISCUSSION}

Early complications of AMI are a serious problem that threatens patients' lives and requires timely medical intervention to prevent death. Type 2 DM complicates the course of AMI and affects the structural and functional state of the myocardium in the postinfarction period ${ }^{24}$. Various signaling pathways involved in the development, prevention of inflammation and myocardial remodeling are currently being studied from different perspectives. A previous study reported that independent predictors of AV blockade development were DM, increased age, right coronary artery occlusion, and thrombolysis in myocardial infarction flow grades of 0 and $1^{25}$. In ROC curve analysis, the AUC was 0.758 for detecting highdegree AV blockade, and the AUC was 0.737 for the development of AF in STEMI patients ${ }^{26}$. According to Frydland M. et al. ${ }^{27}$, a model for predicting the development of cardiogenic shock in STEMI patients was developed, where the AUC was 0.86. Buono Marco G Del et al. ${ }^{28}$ determined that the predictor of AHF was the N-terminal propeptide of natriuretic hormone level in patients following STEMI (AUC was 0.771). In another ROC curve analysis, the AUC was $0.748^{29}$. Sun L. et al. found that AHF Killip $\geq 3$, hyperglycemia, and LVEF less than $50 \%$ were predictors of ventricular tachycardia (VT)/VF development, and the AUC in the predictive model for VT/VF development in patients with AMI was $0.779^{30}$. The AUC in 
Table 2: Coefficients of the binary logistic regression model designed to predict early complications in type 2 diabetes mellitus patients with acute myocardial infarction

\begin{tabular}{lcccc}
\hline Indictors & Coefficients & Standard errors & Wald's criterion & P -value \\
CTRP3, ng/ml & 0.030 & 0.012 & 6.270 & 0.012 \\
$\mathrm{RR}, \mathrm{bpm}$ & 1.414 & 0.518 & 7.455 & 0.006 \\
$\mathrm{BMI}, \mathrm{kg} / \mathrm{m}^{2}$ & 0.322 & 0.159 & 4.116 & 0.042 \\
$\mathrm{HR}, \mathrm{bpm}$ & 0.091 & 0.036 & 6.384 & 0.012 \\
Constant & -50.800 & 16.067 & 9.997 & 0.002 \\
\hline
\end{tabular}

Data are presented as medians and interquartile ranges $\left(25^{\text {th }}\right.$ and $75^{\text {th }}$ percentiles $)$ and percentage error. Abbreviations: AF: atrial fibrillation; AHF: acute heart failure; AV block: atrioventricular blockade; CTRP3: C1q tumor necrosis factorrelated protein 3; LVA: left ventricular aneurysm; LVEF: left ventricular ejection fraction; MI: myocardial infarction; VF: ventricular fibrillation; WC: waist circumference; TC: thigh circumference; WC/TC: ratio of waist to thigh circumference; RR: respiratory rate, breaths per minute; HR: heart rate, beats per minute; BMI: body mass index

Table 3: Classification results of the binary logistic regression model designed to predict early complications in type 2 diabetes mellitus patients with acute myocardial infarction

\begin{tabular}{|c|c|c|c|c|}
\hline \multicolumn{2}{|l|}{ Groups under study } & \multicolumn{3}{|c|}{ Predicted groups } \\
\hline \multirow{4}{*}{ Early complications } & & \multicolumn{2}{|c|}{ Early complications } & \multirow[t]{2}{*}{ Correctly predicted $(\%)$} \\
\hline & & no & yes & \\
\hline & no & 47 & 1 & 97.9 \\
\hline & yes & 4 & 22 & 84.6 \\
\hline Total percentage & & & & 93.2 \\
\hline
\end{tabular}

Table 4: Classification results of the model in the validation group

\begin{tabular}{|c|c|c|c|c|}
\hline \multicolumn{2}{|l|}{ Groups under study } & \multicolumn{3}{|c|}{ Predicted groups } \\
\hline \multirow{4}{*}{ Early complications } & & \multicolumn{2}{|c|}{ Early complications } & \multirow[t]{2}{*}{ Correctly predicted (\%) } \\
\hline & & no & yes & \\
\hline & no & 16 & 1 & 94.1 \\
\hline & yes & 1 & 17 & 94.4 \\
\hline Total percentage & & & & 94.3 \\
\hline
\end{tabular}

another predictive model for VF development in patients with STEMI was $0.62^{31}$. According to Gjesdal G. et al. ${ }^{32}$, the AUC was 0.74 when predicting AHF in patients with STEMI. Despite the numerous studies mentioned above, complicated AMI in type $2 \mathrm{DM}$ patients remains insufficiently studied.

CTRP3 is a new adipokine with various properties that regulate carbohydrate and lipid metabolism and myocardial functions. Prolonged hyperglycemia and insulin resistance stimulate the release of cartonectin $^{33}$. Plasma CTRP3 levels were lower in patients with persistent AF than in patients with paroxysmal $\mathrm{AF}^{34}$. Low adiponectin levels were observed in patients with heart failure and reduced EF as well as in patients with VT. A model of VT prognosis was constructed based on cartonectin content, where the borderline value of CTRP 3 was $200 \mathrm{ng} / \mathrm{ml}$, and it predicted the development of VT with a sensitivity of $88.1 \%$ and specificity of $80.2 \%^{35}$. Choi KM et al. ${ }^{36}$ reported decreased adiponectin levels in patients with acute coronary syndrome.

In this study, low serum CTRP3 levels were determined in type $2 \mathrm{DM}$ patients with AMI. The study included developing a model to predict the probability of early complications of AMI in type $2 \mathrm{DM}$ patients based on the CTRP3 level, RR, BMI and HR. The AUC value was 0.962 [0.919; 1.000], which predicted early complications of AMI in type $2 \mathrm{DM}$ patients. The overall percentage of the obtained model performance was $93.2 \%$. The studied model yielded a sensitivity of $84.6 \%$ and a specificity of $97.9 \%$. The main advantage of the study was the model performance evaluation with the validation group. The prognosis 
A

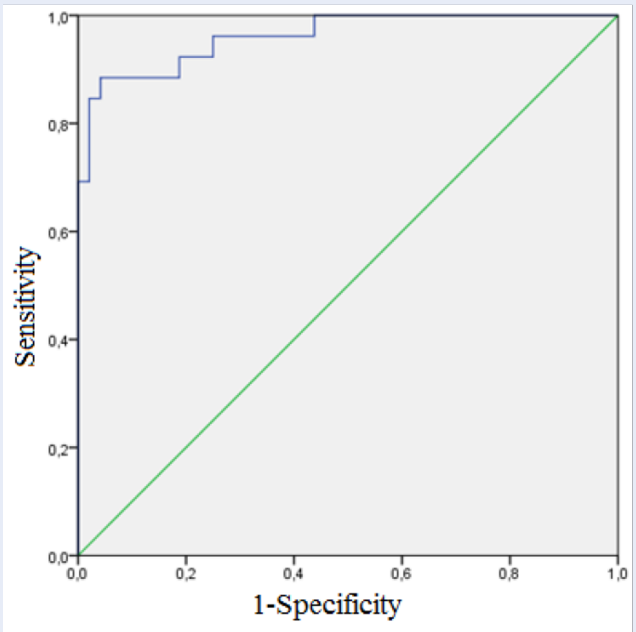

B

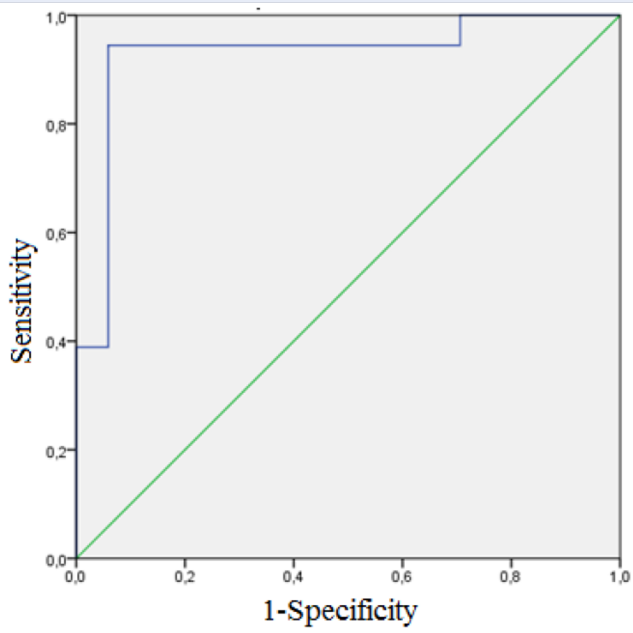

Figure 1: Receiver operating characteristic curves (ROCs) of the model for prediction of early complications in the training (A) and validation (B) groups. A. The results of the ROC curve showing $A U C$ of the model $=0.962$, $95 \% \mathrm{Cl}=0.919-1.000$, sensitivity $=84.6 \%$, specificity $=97.9 \%$, overall percentage of the model performance $=$ $93.2 \%$. B. The results of the ROC curve showing AUC of the model $=0.928,95 \% \mathrm{Cl}=0.829-1.000$, sensitivity $=$ $94.4 \%$, specificity $=94.1 \%$, overall percentage of the model performance $=94.3 \%$.

was confirmed in $94.3 \%$ of cases. The AUC-ROC was 0.928 [0.829; 1.000$]$, demonstrating the high accuracy in predicting early complications of AMI in type 2 DM patients. The obtained model would allow the prediction of possible cardiovascular complications of AMI in type $2 \mathrm{DM}$ patients and prevention of lethal cases. This study was subjected to several limitations as follows. First, the sample size was relatively small $(\mathrm{n}=109)$ and should therefore be increased in the future to confirm the findings. Second, since the study included only type $2 \mathrm{DM}$ patients with STEMI, further testing among patients with STEMI without type 2 DM should be performed to assess the early complications of AMI. In addition, it would be interesting to examine cohorts of patients with non-ST elevation acute myocardial infarction in both type 2 DM presence and absence, which requires further research.

The benefits of the model derived from the method of logistic regression were rapid production and correct interpretation of the results. The impact of each factor was clearly expressed by a coefficient value allowing us to specifically determine which one and to what extent influenced decision-making. A weight vector was set via the multiple least squares method, which is well characterized with many standard implementations and admits a generalization including feature selection, regularization, and weight nonnegativity limitation.
Disadvantages of the model were restricted set of inputs, possible challenges associated with abnormal data, occasionally the need arose to exclude outliers or miss features, regularize weights, standardize data, and what is more, estimated probability could be inadequate if the likelihood function was not exponential.

\section{CONCLUSIONS}

This study has shown that integral measurements of circulating CTRP 3 content, RR, BMI, and HR upon admission of STEMI patients with type 2 DM after PCI could predict early complications of AMI. These findings suggest a new approach to stratify the risk of early AMI complications in type $2 \mathrm{DM}$ patients after successful coronary revascularization.

\section{ABBREVIATIONS}

AF: atrial fibrillation, AHF: acute heart failure, AMI: acute myocardial infarction, AUC: area under the curve, AVblockade: atrioventricular blockade, BMI: body mass index, CTRP3: C1q tumor necrosis factorrelated protein 3, CVDs: cardiovascular diseases, DM: diabetes mellitus, EF: ejection fraction, HR: heart rate, LVA: left ventricular aneurysm, LV: left ventricle, PPAR: peroxisome proliferator activated receptor, ROC: receiver operating characteristic analysis, RR : respiratory rate, STEMI : ST-elevation myocardial infarction, TC: thigh circumference, VF: 
ventricular fibrillation, VT: ventricular tachycardia, WC: waist circumference

\section{ACKNOWLEDGMENTS}

None.

\section{AUTHOR'S CONTRIBUTIONS}

All authors equally contributed to this work. All authors read and approved the final manuscript.

\section{FUNDING}

None.

\section{AVAILABILITY OF DATA AND MATERIALS}

Data and materials used and/or analyzed during the current study are available from the corresponding author on reasonable request.

\section{ETHICS APPROVAL AND CONSENT TO PARTICIPATE}

The study was conducted in compliance with the basic bioethical provisions of the Council of Europe Convention on Human Rights and Biomedicine (March 4, 1997), the Helsinki Declaration of the World Medical Association on the ethical principles of scientific medical research with human participation (1964-2008), and the order of Ministry of Health of Ukraine No. 690 dated Sept. 23, 2009. The conclusion of the Commission on Ethics and Bioethics of Kharkiv National Medical University confirmed that the study was conducted in compliance with human rights, in accordance with the current legislation in Ukraine, met international ethical requirements and did not violate ethical standards in science and standards of biomedical research (minutes of the meeting of the commission on ethics and bioethics of KhNMU No. 2 dated 02 April 2018). The purpose of each examination was explained in detail, and informed consent was obtained from all participants.

\section{CONSENT FOR PUBLICATION}

Not applicable.

\section{COMPETING INTERESTS}

The authors declare that they have no competing interests.

\section{REFERENCES}

1. Fact sheets WHO The top 10 causes of death 9 December 2020 Available from: https://www.who.int/ru/news-room/fact-she ets/detail/the-top-10-causes-of-death.

2. Thoegersen M, Josiassen J, Helgestad OK, Ravn HB, Schmidt H Holmvang $L$. The association of diabetes and admission blood glucose with 30-day mortality in patients with acute myocardial infarction complicated by cardiogenic shock. European Heart Journal Acute Cardiovascular Care. 2020;9(6):626-35. PMID: 32450719. Available from: 10.1177/2048872620925265.

3. Echouffo-Tcheugui JB, Kolte D, Khera S, Aronow HD, Abbott JD, Bhatt DL, et al. al. Diabetes mellitus and cardiogenic shock complicating acute myocardial infarction. The American Journal of Medicine. 2018;131(7):P778-786.e1. PMID: 29596788. Available from: 10.1016/j.amjmed.2018.03.004.

4. Khalid SH, Liaqat I, Mallhi TH, Khan AH, Ahmad J, Khan YH Impact of diabetes mellitus on clinico-laboratory characteristics and in-hospital clinical outcomes among patients with myocardial infarction. JPMA The Journal of the Pakistan Medical Association. 2020;70:2376-82. PMID: 33475547. Available from: 10.47391/JPMA.370.

5. Liang W, Ye D. The potential of adipokines as biomarkers and therapeutic agents for vascular complications in type 2 diabetes mellitus. Cytokine \& Growth Factor Reviews. 2019;48:32-39. PMID: 31229411. Available from: 10.1016/j. cytogfr.2019.06.002.

6. Li Y, Wright GL, Peterson JM. C1q/TNF-related protein 3 (CTRP3) function and regulation. Comprehensive Physiology. 2017;7(3):863-78. PMID: 28640446. Available from: 10.1002/ cphy.c160044.

7. Guo B, Zhuang T, Xu F, Lin X, Li F, Shan SK. New insights into implications of CTRP3 in obesity, metabolic dysfunction, and cardiovascular diseases: potential of therapeutic interventions. Frontiers in Physiology. 2020;11:570270. PMID: 33343381. Available from: 10.3389/fphys.2020.570270.

8. Zhang $\mathrm{CL}$, Feng $\mathrm{H}$, Li L, Wang JY, Wu D, Hao YT. Globular CTRP3 promotes mitochondrial biogenesis in cardiomyocytes through AMPK/PGC- $1 \alpha$ pathway. Biochimica et Biophysica Acta G, General Subjects. 2017;1861(1):3085-94. PMID: 27793739. Available from: 10.1016/j.bbagen.2016.10.022.

9. Wu D, Lei H, Wang JY, Zhang CL, Feng H, Fu FY. CTRP3 attenuates post-infarct cardiac fibrosis by targeting Smad3 activation and inhibiting myofibroblast differentiation. Journal of Molecular Medicine (Berlin, Germany). 2015;93(12):1311-25. PMID: 26138247. Available from: 10.1007/s00109-015-1309-8.

10. Yuan YP, Ma ZG, Zhang X, Xu SC, Zeng XF, Yang Z. CTRP3 protected against doxorubicin-induced cardiac dysfunction, inflammation and cell death via activation of Sirt1. Journal of Molecular and Cellular Cardiology. 2018;114:38-47. PMID: 29061338. Available from: 10.1016/j.yjmcc.2017.10.008.

11. Ma ZG, Yuan YP, Xu SC, Wei WY, Xu CR, Zhang X. CTRP3 attenuates cardiac dysfunction, inflammation, oxidative stress and cell death in diabetic cardiomyopathy in rats. Diabetologia. 2017;60(6):1126-37. PMID: 28258411. Available from: 10.1007/s00125-017-4232-4.

12. Chen L, Qin L, Liu X, Meng X. CTRP3 alleviates ox-LDL-induced inflammatory response and endothelial dysfunction in mouse aortic endothelial cells by activating the PI3K/Akt/eNOS pathway. Inflammation. 2019;42(4):1350-9. PMID: 30887395. Available from: 10.1007/s10753-019-00996-1.

13. Moradi N, Najafi M, Sharma T, Fallah S, Koushki M, Peterson JM. Circulating levels of CTRP3 in patients with type 2 diabetes mellitus compared to controls: A systematic review and meta-analysis. Diabetes Research and Clinical Practice. 2020;169:108453. PMID: 32949652. Available from: 10.1016/j. diabres.2020.108453.

14. Ahmed SF, Shabayek MI, Ghany MEA, El-Hefnawy MH, ElMesallamy HO. Role of CTRP3, CTRP9 and MCP-1 for the evaluation of T2DM associated coronary artery disease in Egyptian postmenopausal females. PLoS One. 2018;13(12):e0208038. PMID: 30557342. Available from: 10.1371/journal.pone. 0208038 .

15. Kratochvilova H, Kasperova BJ, Lacinova Z, Lankova I, Trnovska J, Netuka I, et al. CTRP3, a Novel adipokine with antiinflammatory and cardioprotective properties, in patients with cardiovascular diseases and type 2 diabetes mellitus. Diabetes. 2020;69:91. Available from: 10.2337/db20-91-OR. 
16. Ibanez B, James S, Agewall S, Antunes MJ, Bucciarelli-Ducci C, Bueno $\mathrm{H}$, et al. 2017 ESC Guidelines for the management of acute myocardial infarction in patients presenting with ST-segment elevation: the Task Force for the management of acute myocardial infarction in patients presenting with ST-segment elevation of the European Society of Cardiology (ESC). European Heart Journal. 2018;39(2):119-77. PMID: 28886621. Available from: 10.1093/eurheartj/ehx393.

17. Online version of IDF Diabetes Atlas: Nineth edition, 2019. Available from: https://www.diabetesatlas.org/en/.

18. Association AD. Classification and diagnosis of diabetes: standards of medical care in diabetes. Diabetes Care. 2018;41:1327. PMID: 29222373. Available from: 10.2337/dc18-S002.

19. Davies MJ, D'Alessio DA, Fradkin J, Kernan WN, Mathieu C, Mingrone $G$. Management of hyperglycaemia in type 2 diabetes, 2018. A consensus report by the American Diabetes Association (ADA) and the European Association for the Study of Diabetes (EASD). Diabetologia. 2018;61(12):2461-98. PMID: 30288571. Available from: 10.1007/s00125-018-4729-5.

20. Cosentino F, Grant PJ, Aboyans V, Bailey CJ, Ceriello A, Delgado V, et al. 2019 ESC Guidelines on diabetes, pre-diabetes, and cardiovascular diseases developed in collaboration with the EASD. European Heart Journal. 2020;41(2):255-323. PMID: 31497854. Available from: 10.1093/eurheartj/ehz486.

21. Standards of medical care in diabetes - 2019. Abridged for primary care providers American diabetes association. Clinical diabetes. 2019;37:11-34. PMID: 30705493. Available from: 10.2337/cd18-0105.

22. Yumuk V, Tsigos C, Fried M, Schindler K, Busetto L, Micic D, et al. European guidelines for obesity management in adults. Obesity Facts. 2015;8(6):402-24. PMID: 26641646. Available from: $10.1159 / 000442721$

23. Schutz DD, Busetto L, Dicker D, Farpour-Lambert N, Pryke R, Toplak H. European practical and patient centred guidelines for adult obesity management in primary care. Obesity Facts. 2019;12(1):40-66. PMID: 30673677. Available from: 10.1159/ 000496183.

24. Pedersen F, Butrymovich V, KelbH, Wachtell K, Helqvist S, Kastrup J. Short- and long-term cause of death in patients treated with primary PCI for STEMI. Journal of the American College of Cardiology. 2014;64(20):2101-8. PMID: 25457398. Available from: 10.1016/j.jacc.2014.08.037.

25. Kosmidou I, Redfors B, Dordi R, Dizon JM, McAndrew T, Mehran R. Incidence, predictors, and outcomes of highgrade atrioventricular block in patients with ST-segment elevation myocardial infarction undergoing primary percutaneous coronary intervention (from the HORIZONS-AMI trial). The American Journal of Cardiology. 2017;119(9):1295-301. PMID: 28267964. Available from: 10.1016/j.amjcard.2017.01. 019.

26. Yildirim E, Turkkan C, Ozcan KS, Ceylan US, Zengin A. The predictive value of PRECISE-DAPT score for arrhythmic complications in patients with ST-elevation myocardial infarction. Coronary Artery Disease. 2019;30(7):499-504. PMID: 31567370. Available from: $10.1097 / \mathrm{mca} .0000000000000788$.
27. Frydland $M, M \varnothing$ ller JE, Lindholm MG, Hansen $R$, Wiberg $S$, Helgestad OKL. Biomarkers predictive of late cardiogenic shock development in patients with suspected ST-elevation myocardial infarction. European Heart Journal Acute Cardiovascular Care. 2020;9(6):557-66. PMID: 31961195. Available from: $10.1177 / 2048872619896063$.

28. Buono MGD, Trankle CR, Buckley L, Kadariya D, Canada JM, Carbone $\mathrm{S}$, et al. Early changes in NT-proBNP levels predict new-onset heart failure in patients with STEMI. Minerva Cardioangiologica. 2020;p. Online first. PMID: 32657561. Available from: 10.23736/S0026-4725.20.05303-7.

29. Sharma YP, Kanabar K, Santosh K, Kasinadhuni G, Krishnappa D. Role of N-terminal pro-B-type natriuretic peptide in the prediction of outcomes in ST-elevation myocardial infarction complicated by cardiogenic shock. Indian Heart Journal. 2020;72(4):302-5. PMID: 32861389. Available from: 10.1016/j. ihj.2020.07.002.

30. Sun L, Mao L, Zou A, Chi B, Chen X, Ji Y. [Development and validation of a clinical predictive model for the risk of malignant ventricular arrhythmia during hospitalization in patients with acute myocardial infarction]. Zhonghua Wei Zhong Bing Ji Jiu Yi Xue. 2021;33(4):438-42. PMID: 34053487. Available from: 10.3760/cma.j.cn121430-20201217-00760.

31. Hulleman M, Salcido DD, Menegazzi JJ, Souverein PC, Tan HL, Blom MT. Predictive value of amplitude spectrum area of ventricular fibrillation waveform in patients with acute or previous myocardial infarction in out-of-hospital cardiac arrest. Resuscitation. 2017;120:125-31. PMID: 28844935. Available from: 10.1016/j.resuscitation.2017.

32. Gjesdal G, Braun OO, Smith JG, Scherstén F, Tydén P. Blood lactate is a predictor of short-term mortality in patients with myocardial infarction complicated by heart failure but without cardiogenic shock. BMC Cardiovascular Disorders. 2018;18(1):8. PMID: 29347907. Available from: 10.1186/ s12872-018-0744-1.

33. Liang W, Ye DD. The potential of adipokines as biomarkers and therapeutic agents for vascular complications in type 2 diabetes mellitus. Cytokine \& Growth Factor Reviews. 2019;48:32-39. PMID: 31229411. Available from: 10.1016/j. cytogfr.2019.06.002.

34. Chen L, Liu S, Xu W, Zhang Y, Bai J, Li L. Association of Plasma C1q/TNF-related protein 3 (CTRP3) in patients with atrial fibrillation. Mediators of Inflammation. 2020;2020:8873152. PMID: 33424438. Available from: 10.1155/2020/8873152.

35. Yildirim A, Sumbul HE, Koca $H$, Kucukosmanoglu $M$, Icen YK, Koc M. Complement c1q/tumor necrosis factor-related protein-3 (CTRP3) is significantly decreased in patients with heart failure and closely related with ventricular tachycardia. Acta Cardiologica Sinica. 2021;37(285):278. PMID: 33976511. Available from: 10.6515/ACS.202105_37(3).

36. Choi KM, Hwang SY, Hong HC, Choi HY, Yoo HJ, Youn BS. Implications of C1q/TNF-related protein-3 (CTRP-3) and progranulin in patients with acute coronary syndrome and stable angina pectoris. Cardiovascular Diabetology. 2014;13(1):14 PMID: 24417980. Available from: 10.1186/1475-2840-13-14. 
Ready to submit your manuscript? Choose Biomedpress and benefit from:

- Fast, convenient online submission

- Through peer-review by experienced researchers

- Rapid publication on acceptance

- Free of charge (without publication fees)

Learn more http://www.biomedpress.org/journals/
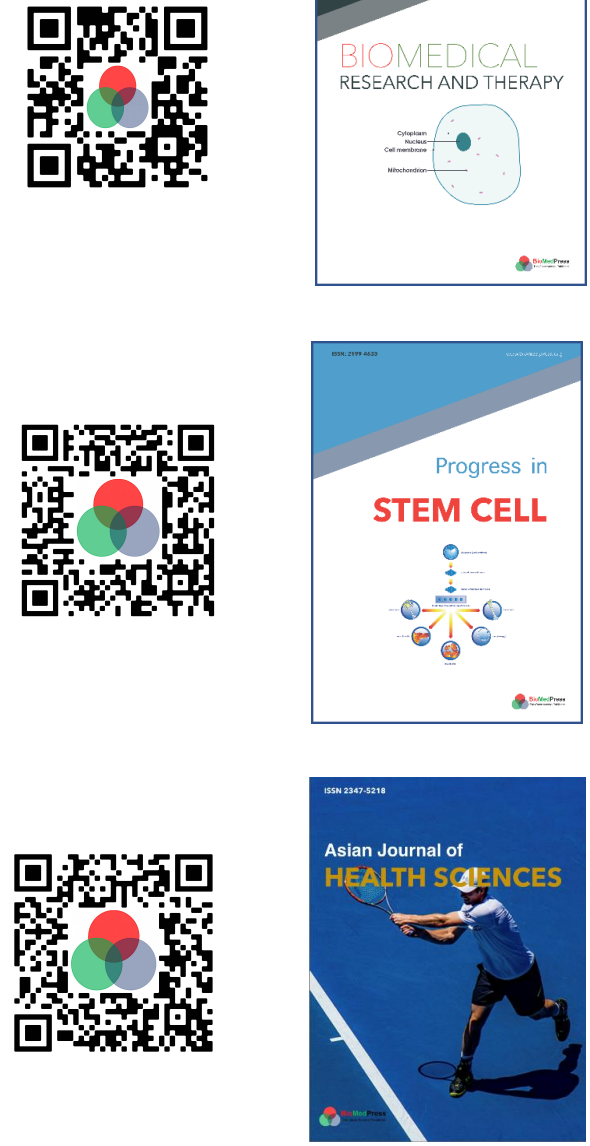

Asian Journal of Health Sciences

ISSN: 2347-5218

Indexed: Google Scholar

Acceptance Rate (2020): 72.89\%

Article Publishing Charge: Free

Submission to first editorial decision: 16.5 days

Biotechnological Research

ISSN: 2395-6763

Indexed: Google Scholar

Acceptance Rate (2020): $67.02 \%$

Article Publishing Charge: Free

Submission to first editorial decision: 28.5 days 